Review

\title{
IL-22: An Evolutionary Missing-Link Authenticating the Role of the Immune System in Tissue Regeneration
}

\author{
Pawan Kumar ${ }^{1}$, Kamalakannan Rajasekaran ${ }^{1}$, Jeanne M Palmer ${ }^{1,2}$, Monica S Thakar ${ }^{1,3,}$, and Subramaniam \\ Malarkannan $1,2,4, \mathbb{}$ \\ 1. Laboratory of Molecular Immunology and Immunotherapy, Blood Research Institute, 8727 Watertown Plank Road, Milwaukee, WI \\ 53226, USA. \\ 2. Department of Medicine, Medical College of Wisconsin, Milwaukee, WI 53226, USA; \\ 3. Department of Pediatrics, Medical College of Wisconsin, Milwaukee, WI 53226, USA; \\ 4. Department of Microbiology/Molecular Genetics, Medical College of Wisconsin, Milwaukee, WI 53226, USA.
}

$\triangle$ Corresponding author: Subramaniam Malarkannan (Subra.malar@bcw.edu) or Thakar, Monica (mthakar@mcw.edu).

(C) Ivyspring International Publisher. This is an open-access article distributed under the terms of the Creative Commons License (http://creativecommons.org/ licenses/by-nc-nd/3.0/). Reproduction is permitted for personal, noncommercial use, provided that the article is in whole, unmodified, and properly cited.

Received: 2012.10.22; Accepted: 2012.12.01; Published: 2012.12.25

\begin{abstract}
Tissue regeneration is a critical component of organ maintenance. The ability of lymphocytes to kill pathogen-infected cells has been well-studied. However, the necessity for lymphocytes to participate in reconstruction of destroyed tissues has not been explored until recently. Interleukin (IL)-22, a newly defined cytokine exclusively produced by subsets of lymphocytes, provides the strongest proof yet for the tissue regenerative potentials of the immune system. IL-22 plays an obligatory role in epithelial homeostasis in the gut, liver and lung. The receptor for IL-22 (IL-22RI and IL-IOR2) is predominantly expressed by epithelial cells. While the pro-inflammatory effect is questioned, the pro-constructive potential of IL-22 is well established. It is evident from the response to IL-22, that epithelial cells not only produce anti-microbial peptides but also actively proliferate. Aryl hydrocarbon receptor (AhR) and retinoic acid-related orphan receptor (ROR $\gamma \mathrm{t}$ ) transcription factor are required for IL-22 generation from Lymphoid Tissue inducer cells LTi, Th22 and NK-like cells. However, IL-22 production from conventional NK cells is independent of AhR and ROR $\gamma t$. In this review, we present a case for a paradigm shift in how we define the function of the immune system. This would include tissue regeneration as a legitimate immune function.
\end{abstract}

Key words: Interleukin (IL)-22, immune function, tissue regeneration

\section{Introduction: Redefining the immune paradigm}

Lymphocytes have evolved to mediate complex immune responses to protect the body from pathogens, parasites, and tumor growth. However, there is growing evidence that lymphocytes have also evolved to perform a number of other 'unexpected' physiological functions. One such function is the ability of lymphocytes to produce cytokines uniquely responsible for tissue regeneration and homeostasis. IL-22 is produced by specialized and conventional innate lymphocytes. Its receptor is uniquely expressed in select non-immune cells including epithelial cells. IL-22 promotes the production of anti-microbial peptides from epithelial cells and more importantly stimulates their active proliferation. Thus, IL-22 becomes an exceptional example of a tool produced by the immune system to maintain and regenerate tissues under normal and pathological conditions. In this review, we discuss recent advances in IL-22 biology, its relevance in disease conditions, and its future utilization as a therapeutic agent. The ability of IL-22 to mediate the pro-inflammatory responses is 
under debate. Currently, studies indicate that the function of IL-22 in tissue regeneration or proinflammation is disease or organ specific (1). For example, in gut, liver, and lung disease models, IL-22 has been reported to have anti-microbial, tissue protective, and tissue regenerative effects (2-4). Whereas in a skin psoriasis model, IL-22 demonstrates both inflammatory and hyperproliferative effects (5).

\section{IL-22 and its receptor: it takes a family}

IL-22 was first identified in 2000 during a search for IL-9-inducible genes in mouse T cells (6). An increase in IL-22 mRNA was shown in peripheral blood mononuclear cell-derived CD4 $\mathrm{T}$ and NK cells following anti-CD3 antibody or IL-2/IL-12-mediated stimulations, respectively (7). One of the identified genes showed $22 \%$ amino acid homology to IL-10, and was named 'IL-10-related T cell-derived Inducible Factor' (IL-TIF) (6). Later, its human counterpart, which showed $79 \%$ amino acid homology with mouse IL-TIF was independently identified by two groups $(8 ; 9)$ and designated as IL-22. Cytokines such as IL-19, IL-20, IL-24, IL-26, IL-28 $\alpha$, IL-28 $\beta$ and IL-29 that are structurally related to IL-10 also belong to the IL-10 family (10-14). A close evolutionary relationship between some of these cytokines reveals a conserved functional significance of IL-22 and its family members (Figure 1).



Figure I. Evolutionary relationship between IL-I0 family members. IL-22, IL-20, IL-24 and IL-26 belong to IL-I0 family of cytokines. Phylogenetic tree indicates the evolutionary relationship of IL-10 family members among different species. This tree was generated using PhylomeDB alignment program software based on distance-matrix and amino acid sequences of murine IL-22. Dendrogram generated using UPGMA method with a 'Systematic tie breaking' based on the percent differences between amino acid sequences. Distances were calculated using an uncorrected ' $p$ ' and gaps distributed proportionately among different amino acid sequences. The number below the dendrogram represents the unit change in the amino acid sequences among indicated species. 
IL-10 uses heterodimeric receptor complexes for signaling. Although, IL-22 is structurally similar to IL-10, it does not use the same receptor complex for signaling. Functional studies confirmed IL-10R2 as a common receptor chain for both IL-10 and IL-22 (Figure 2). Later a second unique receptor component was identified and named as IL-22R1 (9). IL-22R expression is limited to non-hematopoietic cell lineages; mainly to epithelial cells in lung, intestine, skin, pancreas, and liver (7). IL-22R uses JAK-STAT signaling pathway and STAT1, STAT3, and STAT4 transcription factors (15). These signaling pathways regulate epithelial cell proliferation and production of anti-microbial peptides $(16 ; 17)$.

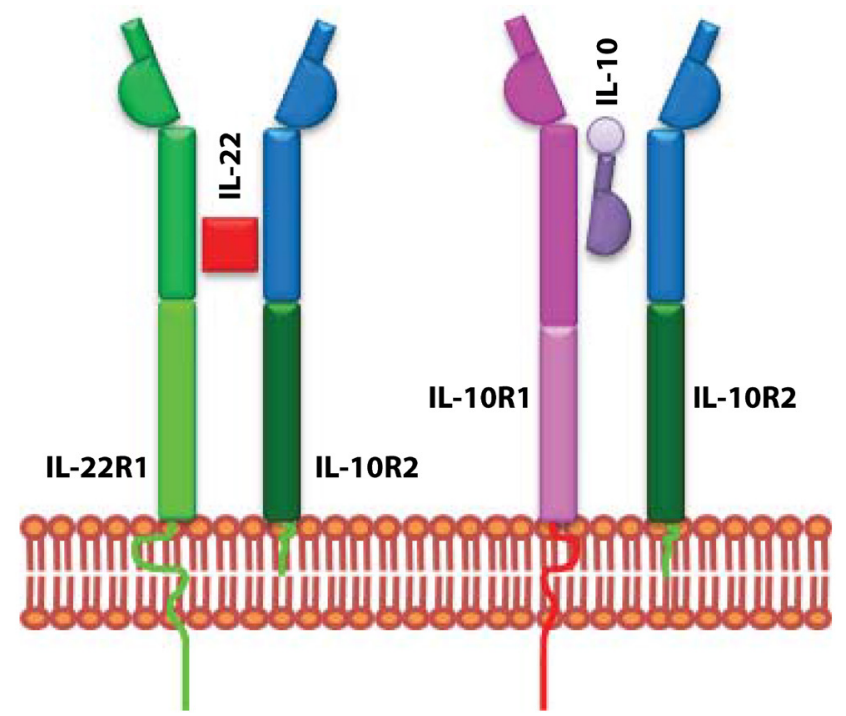

Figure 2. IL-22 and IL-IO receptors evolved to utilize shared subunits. IL- 10 and IL-22 receptors are composed of heterodimeric chains. IL-IO is made up of IL-IORI and IL-IOR2. IL-22 receptor complex consists of IL-22RI and IL-IOR2. The unique signaling and the functional outcome of these two cytokines are maintained by the exclusive use of independent receptor subunits.

\section{IL-22 production: Multiple cell types, unique niches, and distinct developmen- tal requirements}

Various cell types produce IL-22, such as innate lymphoid cells (ILCs), NK, NKT, and $\gamma \delta$ T cells (18). Our earlier studies demonstrate that the production of IL-22 from conventional NK cells plays a vital role in the regeneration of tracheal and alveolar epithelial cells (Figure 3) (19). Thus, the cell types that produce IL-22 are all of hematopoietic origin. Among various T cells subsets, IL-22 is preferentially produced under Th17-polarized conditions. However, cytokines that are responsible for IL-17 generation did not have the same effect on IL-22 production. IL-6 along with high concentration of TGF- $\beta$ promotes Th17 polarization and IL-17 generation. However, IL- 6 alone can induce IL-22 production from T cells. Interestingly, TGF- $\beta$ suppresses IL-22 generation from T cells (20).

ILCs include LTi cells and NK-like cells and originate from a common hematopoietic precursor (21). There are a number of developmental differences among ILCs in terms of expression of cytokines and dependence upon signaling pathways. LTi cells regulate lymphoid tissue formation during fetal development by using the lymphotoxin signaling pathway (22). IL-22 acts downstream of the lymphotoxin pathway $(23 ; 24)$ and is essential for the organization and maintenance of lymphoid follicles during infection (24). Furthermore, development of LTi and NK-like cells but not conventional NK cells depends on the Aryl hydrocarbon receptor (AhR), and the number of lymphoid follicles is reduced in $A h R$ knockout mice (25). Conventional mouse NK cells constitutively express the pan NK cells marker NK1.1 (CD161) and the natural cytotoxicity receptor (NCR) NKp46. NK-like cells express NKp46, but differ in their ability to express NK1.1 (low or negative). Conventional NK cells do not express IL-7 receptor $\alpha$-chain (CD127), and depend on IL-15 for development and require IL-23 or IL-12 and IL-18 for IL-22 production (19). On the other hand, NK-like cells do express CD127 and their development strictly depends on IL-7 but not on IL-15 (26). Further, unlike conventional NK cells, NK-like cells express and depend on RORyt for their development $(21 ; 27)$. NK-like cells can constitutively produce IL-22 (28) and in addition, IL-23 has been shown to be one of the are major stimuli for its generation.

\section{Biological functions of IL-22: Mea Culpa - the destroyer is the defender}

IL-22 is a unique cytokine, only produced by immune cells and exclusively used by non-immune cells. IL-22 exerts both proinflammatory and tissue protective functions. Innate immune cells predominantly produce IL-22 in unique body niches. However, recent studies have extended these findings to more conventional immune cell types such as $\gamma \delta \mathrm{T}$, NK, and NKT cells (18;29-32). Thus, the conventional immune cell types such as NK or T cells are not only able to protect the body by killing pathogen-infected epithelial cells, but also are able to regulate their tissue regeneration by promoting epithelial cell proliferation (Figure 4). Here, we summarize immune IL-22 function in the context of organs and related diseases. 


\section{IL-22 and gut epithelial cell regeneration}

The role of IL-22 in gut homeostasis is well studied and reviewed elsewhere $(33 ; 34)$. ILCs, which include LTi and NK-like cells, are reported to be the major producers of IL-22 in the gut. Colonic epithelial cells express high level of IL-22R (35). Increased expression of IL-22 is detected in Crohn's disease and in ulcerative colitis patients (36-38), suggesting IL-22 plays a critical role in this disease model. Indeed, IL-22 promotes the production of proinflammatory and tissue-remodeling cytokines, enhancing proliferation and migration of colonic epithelial cells in the gut $(37 ; 38)$. Moreover, in vivo gene delivery of IL-22 attenuates Th2-mediated colitis and regulates the expression of genes related to mucus layer formation (39). To further evaluate the role of IL-22 in gut epithelial cell homeostasis, IL-22 knockout mice were generated and challenged with Citrobactor rodentium (40). IL-22 knockout mice displayed impaired gut epithelial cell regeneration, high bacterial load and increased mortality; thus, confirming the previously defined IL-22 functions (40). ILCs are of particular interest in the bacteria-induced colitis model where they are the major contributor of IL-22 (41).
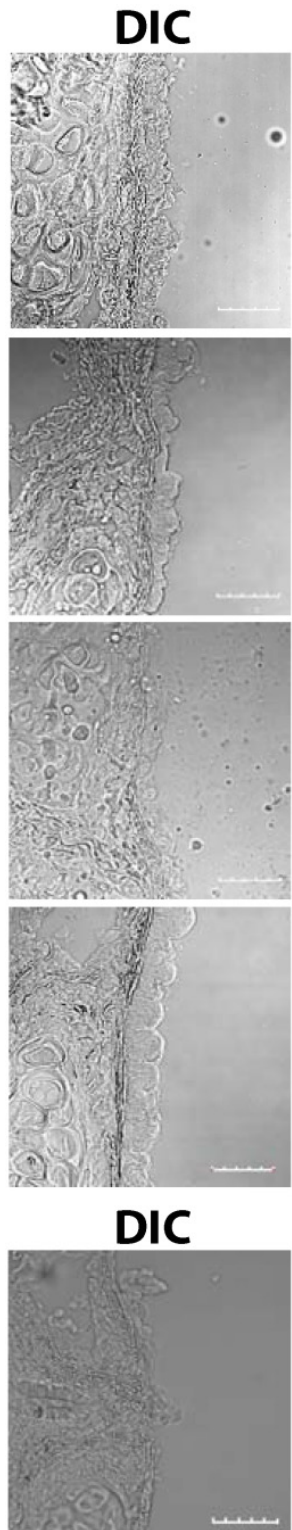
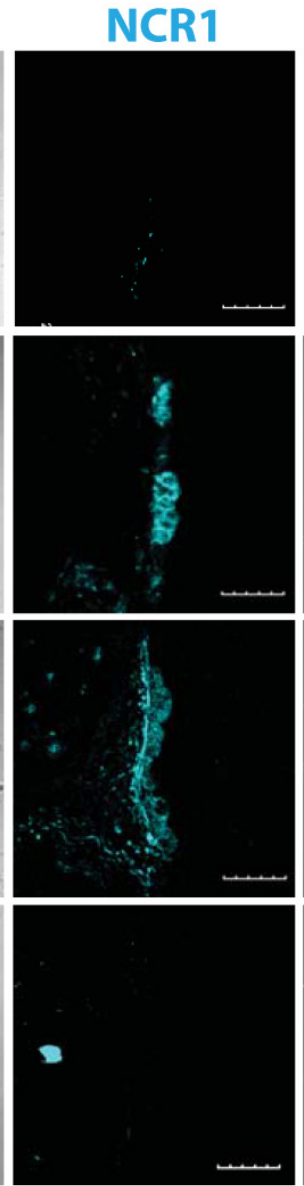

NCR1



NK1.1
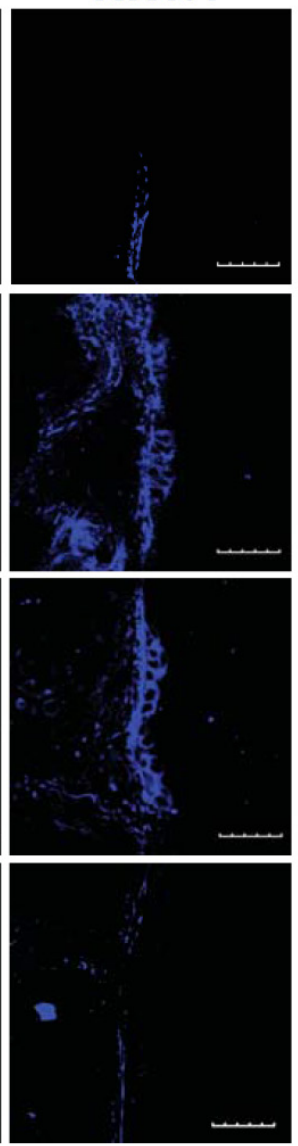

NK1.1

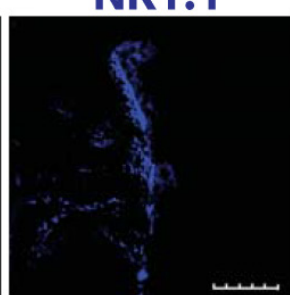

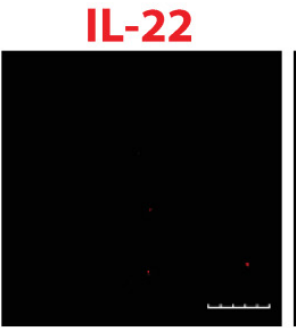
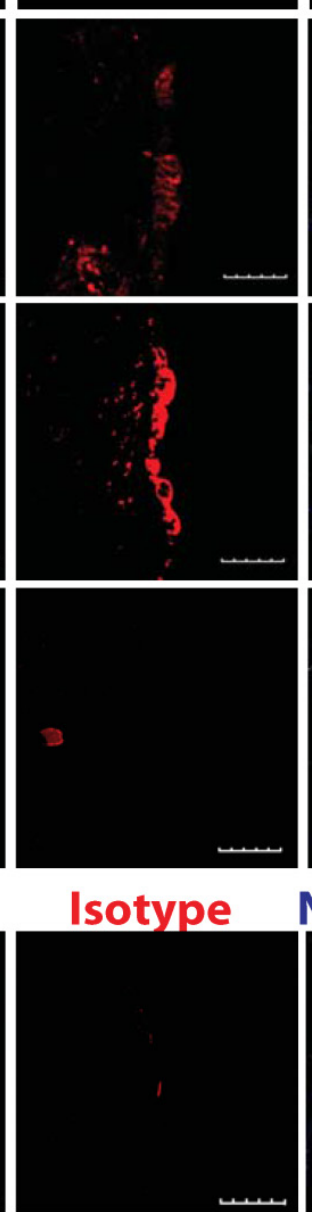

NK1.1/IL-22
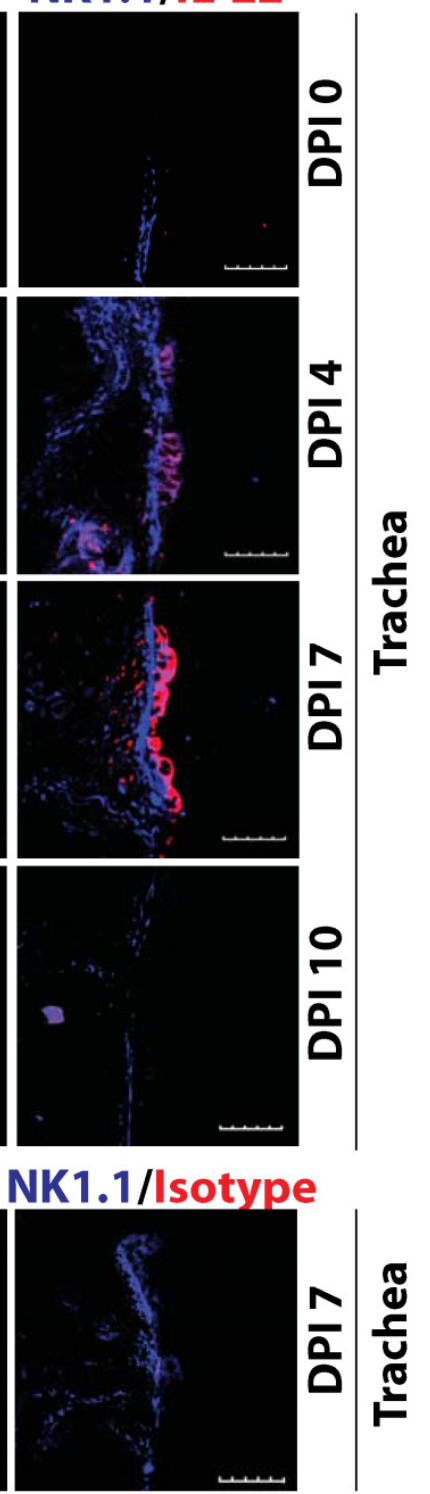

Figure 3. IL-22 is produced by conventional lymphocytes such as NK cells. Multiple lymphocyte subsets including NK cells are able to produce IL-22. Representative confocal images of tracheal sections of mice infected with influenza virus (PR8) were stained for NCRI (azure), NKI.I (blue), and IL-22 (red). Scale bars in the images represent $20 \mu M$. The number of NK cells producing IL-22 steadily increased in the later stages (7-12 days) of influenza virus infection, when epithelial cell layer repair was underway. 
Defined Immune Paradigm



Paradigm shift: Tissue regeneration as immune function

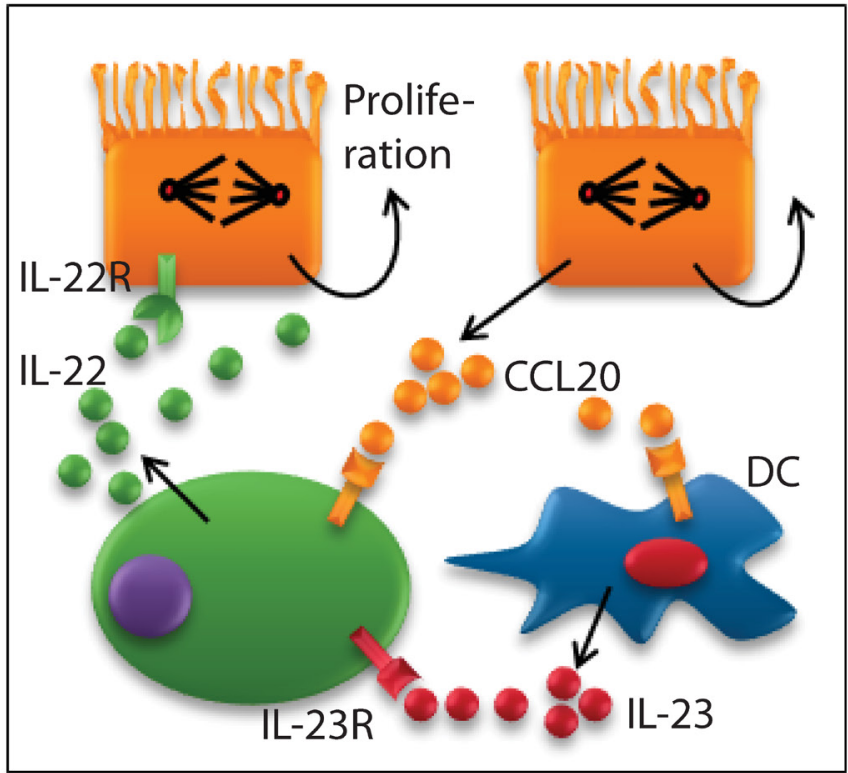

Figure 4. Existing definition of immune system requires a paradigm shift. Defined immune paradigm involves recognition and elimination of virus-infected epithelial cells. However, evidence is mounting that immune cells are involved in the regeneration of destroyed epithelial cell layers. This supports the argument that a paradigm shift in the very definition of the immune system is required.

IL-23 is the major factor identified for IL-22 generation; mice deficient in IL-23p19 had reduced IL-22 production and displayed a similar phenotype to the IL-22 knockout (40). Initially an NK-like $\left(\mathrm{CD}^{-} \mathrm{NKp} 46^{+} \mathrm{NK} 1.1^{-}\right)$subset was reported to be the predominant source of IL-22 in the gut $(27 ; 41)$, but later studies indicate LTi-like cells are the major contributor for IL-22 in the gut (42;43).

However, in the inflammatory bowel disease (IBD) model, both $\mathrm{T}$ and NK cells contribute to IL-22-mediated protection (31). The conflicting reports on the effect of IL-22 on epithelial cells resulting in regeneration versus production of proinflammatory cytokines is not yet thoroughly understood. In this context, it is important to note that while the normal levels of IL-22 support the optimal proliferation of epithelial cells; an augmented IL-22 secretion may promote hyper-proliferation of these cells resulting in hyperplasia. Therefore, a careful interpretation of IL-22 functions in various disease models is required to generate clinical utilization guidelines for IL-22. Development of IL-22 producing NK like cells depends on ROR $\gamma \mathrm{t}(27 ; 28)$ suggesting these cells are derived from LTi cells (44). Furthermore, gut commensal micro flora is required for the differentiation of IL-22-producing NK-like cells $(27 ; 28)$; however, this is debated (25). IL-22 production also contributes to immunopathology in the gut. For example, Toxoplas- ma gondii-induced ileal inflammation was significantly reduced in IL-22 and IL-23p19 knockout but not in IL-17 knockout mice, suggesting IL-23-induced IL-22 leads to pathological responses in the gut (45).

\section{IL-22 and airway epithelial cell regenera- tion}

Tracheal and bronchial epithelial cells in the lung express IL-22 receptor (46). Recent studies have shown that IL-22 is involved in protection against bacteria as well as epithelial cell regeneration. The role of IL-22 in lung epithelial cells was first demonstrated in a bacterial pneumonia model (47) where IL-22 alone or IL-22 in combination with IL-17 increased lung epithelial cell proliferation and expression of host defense-related genes such as $\beta$-defensin 2 , psoriasin and calgranulin. In this study, IL-22 and IL-17 independently regulated mucosal host defenses against Klebsiella pneumoniae, and $\mathrm{CD} 90^{+} \mathrm{T}$ cells were the major producer of IL-22 (47). In a ventilation-induced lung injury model, IL-22 conferred protection by reducing proinflammatory cytokines and matrix metalloproteinase (MMP)-9 production, and by increasing the expression of suppressor of cytokine signaling (SOCS) (48).

Using a bleomycin-induced lung-injury model, earlier studies demonstrate that IL-22 exerts both 
proinflammatory and tissue protective roles (49). IL-22 blockade or bleomycin administration to IL-22 knockout mice results in reduced lung inflammation and weight loss, suggesting a proinflammatory role for IL-22 in acute lung injury (49). Furthermore, the proinflammatory effect of IL-22 requires the presence of IL-17A (50). Interestingly, in the absence of IL-17A, IL-22 is tissue protective (49), suggesting IL-17 governs the inflammatory and tissue protective effect of IL-22 in the acute lung injury model. TCR $\beta{ }^{+} \mathrm{CD} 4^{+} \mathrm{T}$ cells have been reported to be the dominant producer of both IL-17A and IL-22 after bleomycin administration (49). Moreover, adenovirus delivery of IL-22 into C57BL/ 6 mice results in systemic generation of acute phase protein, further demonstrating the proinflammatory effect of IL-22 (51). Both the proinflammatory and protective role of IL-22 was confirmed in an allergic lung inflammation model (50), where upregulation of inflammatory cytokine IL-17A and IL-17F and a down regulation of Th2 cytokines/chemokines were observed in IL-22 deficient mice during onset of allergic inflammation (50). Interestingly, IL-22 neutralization during the sensitization phase reduces lung inflammation; whereas, its neutralization during the antigen challenge phase augments the inflammatory response (50).

IL-22 plays a tissue protective role in hypersensitivity pneumonitis, a chronic lung inflammatory condition (18). In this model, recombinant IL-22 ameliorates Bacillus subtilis-induced lung inflammation in TCR- $\delta$ or $A h R^{\mathrm{d} / \mathrm{d}}$ mice, and inhibition of IL-22 results in an increase in fibrosis and inflammation (18). In this study, $\gamma \delta$ T cells are the major producers of IL-22, and depend on AhR signaling. The protective role of IL-22 was further confirmed in Staphylococcus aureus infection model, where infection of $I L-22$ or $I L-17$ knockout mice resulted in impaired bacterial clearance (52). Staphylococcus aureus infection increases the expression of IL-17 and IL-22; however, when mice are challenged with influenza virus followed by Staphylococcus aureus, the expression of these cytokines is reduced, resulting in an increased susceptibility to infection (52).

A recent study has shown that IL-22 can be produced by conventional NK cells during influenza infection (32). In this study, mice were challenged with a suboptimal dose of influenza virus (5 plaque forming units) and treated with a single dose of IL-22 neutralizing antibody. They found that IL-22 did not play any protective or inflammatory role. However, this study did not analyze the effect of IL-22 blockade on bronchial and tracheal epithelial cells in infected mice (32). Studies from our laboratory confirm that production of IL-22 occurs from conventional NK cells during influenza infection (19). We characterized the phenotype of IL-22-producing cells as $\mathrm{NCR} 1{ }^{+} \mathrm{NK} 1.1^{+} \mathrm{CD} 127^{-}$. In contrast to the findings of Guo et al, where the IL-22 effect was blocked by specific antibody (32), infection of IL-22 knockout mice resulted in severe weight loss and impaired regeneration of tracheal and bronchial epithelial cells. Adoptive transfer of IL-22 sufficient, but not deficient NK cells into $I L-22$ knockout mice restored epithelial cell regeneration. Influenza infection in $I L-22$ knockout mice resulted in more severe lung inflammation, which could be due to decreased IL-10 generation from epithelial cells. The mechanism of epithelial cell regeneration following viral infection remains unclear. Mature epithelial cells actively proliferate in response to IL-22 resulting in tissue regeneration. Moreover, the role of IL-22 in progenitor cell differentiation and maturation of epithelial cells has yet to be fully understood. In summary, IL-22 plays a critical role in tissue repair in lung disease models.

\section{IL-22 and liver hepatocyte regeneration}

Hepatocytes abundantly express IL-22R and stimulation via IL-22, promotes cell growth and survival. Tissue protective and regenerative functions of IL-22 were first reported by Radaeva et al in a liver injury model, whereby blockade of IL-22 results in severe liver injury. Additionally, in vitro stimulation of hepatic cells with recombinant IL-22 enhanced expression of anti-apoptotic and mitogenic gene (2). Furthermore, in vivo gene delivery of IL-22 protects against liver injury by various toxins (4). IL-22 expression is reported in human hepatitis patients, and primary human hepatocytes responded to recombinant IL-22 by active proliferation resulting in liver regeneration. IL-22 also enhances expression of proinflammatory regenerative cytokines (IL-6 and TNF- $\alpha$ ) and SOCS-1/3; however, overexpression of SOCS abrogates IL-22-mediated liver regeneration (38). The tissue protective role of IL-22 in acute liver injury was further reported by Zenewicz et al, in which IL-22 knockout mice were highly susceptible to Conconavalin A-induced hepatitis (53). Interestingly, IL-17 does not play a protective role in acute liver injury (53).

IL-22 also promotes liver regeneration after partial hepatectomy (54), suggesting a therapeutic implication of this cytokine in liver transplantation or patients undergoing hepatic surgery. In addition to tissue regenerative and anti-apoptotic effect, IL-22 regulates the expression of genes responsible for lipogenesis, and long term treatment of IL-22 resulted in decreased levels of triglyceride and cholesterol (55). Furthermore, IL-22 provides protection against alco- 
hol or Conconavalin-A induced liver injury (56-58). In a liver disease model, IL-22 is shown to be anti-apoptotic, tissue regenerative, anti-steatotic, and anti-inflammatory and has the potential to be used to treat hepatic conditions (59). After injury, hepatic stellate cells are activated and produce extracellular matrix components and metalloproteases, thus, playing a critical role in tissue remodeling. Hepatic stellate cells express IL-22R and regulate liver fibrosis through IL-22 signaling (59). In addition, IL-22R is expressed in liver stem/progenitor cells and in vitro stimulation of these cells with IL-22 results in STAT3 activation and cell proliferation (60). Additional studies are required to confirm the in vivo role of IL-22 in liver stem cell function.

\section{IL-22 and skin epithelial cell regeneration}

Keratinocytes and fibroblasts express IL-22R and IL-22 treatment enhances the expression of $\beta$-defensin 2 and 3 in keratinocytes (61). IL-22 enhances migration of keratinocytes and also increases the expression of S100A7, S100A8, S100A9 and MMP-3 in cultured primary keratinocytes $(5 ; 16 ; 62)$. Interestingly, S100A7, also known as psoriasin, is highly responsive to IL-22 stimulation in keratinocytes (5). Psoriasin is a highly upregulated gene in psoriasis patients (63). Indeed, a high levels of IL-22 transcripts and protein were detected in psoriatic skin $(16 ; 64 ; 65)$, and neutralization of IL-22 or IL-22 deficiency resulted in reduced thickening of skin and proinflammatory cytokine generation $(17 ; 65)$, suggesting IL-22 acts as a proinflammatory and hyperproliferative cytokine in these skin diseases. IL-22 also enhances the pathogenesis of atopic dermatitis $(66 ; 67)$.

\section{Immune system: Are we ready for a para- digm change?}

Recognition of non-self from self, fine-tuned specificity, and the principles of memory form the basic tenets of an immune system. The current definition of an immune system excludes the exciting possibility that the immune system has co-evolved to actively support the recovery and regeneration of damaged tissue. Ample evidence exists to prove that the immune system takes part in the continuous maintenance and regeneration of tissues. Recent studies have shown that the homeostasis of epithelial cells in different parts of the body depends on unique and conventional lymphocytes. Epithelial cells form the first barrier level to prevent entry of pathogens. As discussed here, IL-22 plays a critical role in the regeneration of damaged epithelial monolayer and stimulates antimicrobial peptide generation. Infection resulting in tissue injury leads to stem cell differentiation. Studies have indicated stem cells express functional IL-22R and after stimulation give rise to distinct progeny (60). Therefore, future studies should focus on the role of the immune system in the maintenance and differentiation of stem cells by immune mediators. IL-22 constitutes one of the best pieces of evidence of how an exclusively immune cell-derived soluble mediator can uniquely regulate the proliferation and regeneration of a non-immune cell type. These 'non-immune' functions of IL-22 beg to redefine the role of the immune system. Additionally, functions of IL-22 also provide strong evidence that the immune system actively participates in tissue regeneration, repair, and maintenance.

\section{Competing Interests}

The authors have declared that no competing interest exists.

\section{References}

1. Sanjabi S, Zenewicz LA, Kamanaka M, Flavell RA. Anti-inflammatory and pro-inflammatory roles of TGF-beta, IL-10, and IL-22 in immunity and autoimmunity. Curr Opin Pharmacol 2009; 9(4):447-453.

2. Radaeva S, Sun R, Pan Hn, Hong F, Gao B. Interleukin 22 (IL-22) plays a protective role in T cell-mediated murine hepatitis: IL-22 is a survival factor for hepatocytes via STAT3 activation. Hepatology 2004; 39(5):1332-1342.

3. Pickert G, Neufert C, Leppkes $M$ et al. STAT3 links IL-22 signaling in intestinal epithelial cells to mucosal wound healing. J Exp Med 2009; 206(7):1465-1472.

4. Pan HF, Zhao XF, Yuan H et al. Decreased serum IL-22 levels in patients with systemic lupus erythematosus. Clin Chim Acta 2009; 401(1-2):179-180.

5. Boniface K, Bernard FX, Garcia M, Gurney AL, Lecron JC, Morel F. IL-22 inhibits epidermal differentiation and induces proinflammatory gene expression and migration of human keratinocytes. J Immunol 2005; 174(6):3695-3702.

6. Dumoutier L, Louahed J, Renauld JC. Cloning and characterization of IL-10-related T cell-derived inducible factor (IL-TIF), a novel cytokine structurally related to IL-10 and inducible by IL-9. J Immunol 2000; 164(4):1814-1819.

7. Wolk K, Kunz S, Asadullah K, Sabat R. Cutting edge: immune cells as sources and targets of the IL-10 family members? J Immunol 2002; 168(11):5397-5402.

8. Dumoutier L, Van RE, Colau D, Renauld JC. Human interleukin-10-related $\mathrm{T}$ cell-derived inducible factor: molecular cloning and functional characterization as an hepatocyte-stimulating factor. Proc Natl Acad Sci U S A 2000; 97(18):10144-10149.

9. Xie MH, Aggarwal S, Ho WH et al. Interleukin (IL)-22, a novel human cytokine that signals through the interferon receptor-related proteins CRF2-4 and IL-22R. J Biol Chem 2000; 275(40):31335-31339.

10. Jiang H, Lin JJ, Su ZZ, Goldstein NI, Fisher PB. Subtraction hybridization identifies a novel melanoma differentiation associated gene, mda-7, modulated during human melanoma differentiation, growth and progression. Oncogene 1995; 11(12):2477-2486.

11. Gallagher G, Dickensheets H, Eskdale J et al. Cloning, expression and initial characterization of interleukin-19 (IL-19), a novel homologue of human interleukin-10 (IL-10). Genes Immun 2000; 1(7):442-450.

12. Knappe $A, H+\mid r S$, Wittmann $S$, Fickenscher $H$. Induction of a Novel Cellular Homolog of Interleukin-10, AK155, by Transformation of $\mathrm{T}$ Lymphocytes with Herpesvirus Saimiri. Journal of Virology 2000; 74(8):3881-3887.

13. Blumberg $\mathrm{H}$, Conklin $\mathrm{D}, \mathrm{Xu} \mathrm{W}$ et al. Interleukin 20: Discovery, Receptor Identification, and Role in Epidermal Function. Cell 2001; 104(1):9-19.

14. Sheppard P, Kindsvogel $\mathrm{W}, \mathrm{Xu}$ W et al. IL-28, IL-29 and their class II cytokine receptor IL-28R. Nat Immunol 2003; 4(1):63-68. 
15. Lejeune D, Dumoutier L, Constantinescu S, Kruijer W, Schuringa JJ, Renauld JC. Interleukin-22 (IL-22) activates the JAK/STAT, ERK, JNK, and p38 MAP kinase pathways in a rat hepatoma cell line. Pathways that are shared with and distinct from IL-10. J Biol Chem 2002; 277(37):33676-33682.

16. Wolk K, Witte E, Wallace E et al. IL-22 regulates the expression of genes responsible for antimicrobial defense, cellular differentiation, and mobility in keratinocytes: a potential role in psoriasis. Eur J Immunol 2006; 36(5):1309-1323.

17. Zheng $\mathrm{Y}$, Danilenko DM, Valdez P et al. Interleukin-22, a $\mathrm{T}(\mathrm{H}) 17$ cytokine, mediates IL-23-induced dermal inflammation and acanthosis. Nature 2007; 445(7128):648-651.

18. Simonian PL, Wehrmann F, Roark CL, Born WK, O'Brien RL, Fontenot AP. gammadelta T cells protect against lung fibrosis via IL-22. J Exp Med 2010; 207(10):2239-2253.

19. Kumar P, Thakar MS, Ouyang W, Malarkannan S. IL-22 from conventional NK cells is epithelial regenerative and inflammation protective during influenza infection. Mucosal Immunol 2012.

20. Rutz S, Noubade R, Eidenschenk C et al. Transcription factor c-Maf mediates the TGF-[beta]-dependent suppression of IL-22 production in TH17 cells. Nat Immunol 2011; 12(12):1238-1245.

21. Crellin NK, Trifari S, Kaplan CD, Cupedo T, Spits H. Human NKp44+IL-22+ cells and LTi-like cells constitute a stable RORC+ lineage distinct from conventional natural killer cells. J Exp Med 2010; 207(2):281-290.

22. Randall TD, Carragher DM, Rangel-Moreno J. Development of secondary lymphoid organs. Annu Rev Immunol 2008; 26:627-650.

23. Tumanov A, Koroleva E, Guo X et al. Lymphotoxin Controls the IL-22 Protection Pathway in Gut Innate Lymphoid Cells during Mucosal Pathogen Challenge. Cell Host and Microbe 2011; 10(1):44-53.

24. Ota N, Wong K, Valdez PA et al. IL-22 bridges the lymphotoxin pathway with the maintenance of colonic lymphoid structures during infection with Citrobacter rodentium. Nat Immunol 2011; 12(10):941-948.

25. Lee JS, Cella M, McDonald KG et al. AHR drives the development of gut ILC22 cells and postnatal lymphoid tissues via pathways dependent on and independent of Notch. Nat Immunol 2012; 13(2):144-151.

26. Satoh-Takayama N, Lesjean-Pottier S, Vieira P et al. IL-7 and IL-15 independently program the differentiation of intestinal CD3-NKp46+ cell subsets from Id2-dependent precursors. J Exp Med 2010; 207(2):273-280.

27. Sanos SL, Bui VL, Mortha A et al. RORgammat and commensal microflora are required for the differentiation of mucosal interleukin 22-producing NKp46+ cells. Nat Immunol 2009; 10(1):83-91.

28. Satoh-Takayama N, Vosshenrich CA, Lesjean-Pottier S et al. Microbial flora drives interleukin 22 production in intestinal NKp46+ cells that provide innate mucosal immune defense. Immunity 2008; 29(6):958-970.

29. Goto M, Murakawa M, Kadoshima-Yamaoka K et al. Murine NKT cells produce Th17 cytokine interleukin-22. Cellular Immunology 2009; 254(2):81-84.

30. Paget $\mathrm{C}$, Ivanov S, Fontaine J et al. Interleukin-22 Is Produced by Invariant Natural Killer T Lymphocytes during Influenza A Virus Infection: POTENTIAL ROLE IN PROTECTION AGAINST LUNG EPITHELIAL DAMAGES. J Biol Chem 2012; 287(12):8816-8829.

31. Zenewicz LA, Yancopoulos GD, Valenzuela DM, Murphy AJ, Stevens S, Flavell RA. Innate and adaptive interleukin-22 protects mice from inflammatory bowel disease. Immunity 2008; 29(6):947-957.

32. Guo H, Topham DJ. Interleukin-22 (IL-22) production by pulmonary Natural Killer cells and the potential role of IL-22 during primary influenza virus infection. J Virol 2010; 84(15):7750-7759.

33. Cooper MA, Colonna M, Yokoyama WM. Hidden talents of natural killers: NK cells in innate and adaptive immunity. EMBO Rep 2009; 10(10):1103-1110.

34. Vivier E, Spits H, Cupedo T. Interleukin-22-producing innate immune cells: new players in mucosal immunity and tissue repair? Nat Rev Immunol 2009; 9(4):229-234

35. Nagalakshmi ML, Rascle A, Zurawski S, Menon S, de Waal MR. Interleukin-22 activates STAT3 and induces IL-10 by colon epithelial cells. Int Immunopharmacol 2004; 4(5):679-691.

36. Wolk K, Witte E, Hoffmann U et al. IL-22 Induces Lipopolysaccharide-Binding Protein in Hepatocytes: A Potential Systemic Role of IL-22 in Crohn-Æs Disease. J Immunol 2007; 178(9):5973-5981.

37. Andoh $\mathrm{A}$, Zhang $\mathrm{Z}$, Inatomi $\mathrm{O}$ et al. Interleukin-22, a member of the IL-10 subfamily, induces inflammatory responses in colonic subepithelial myofibroblasts. Gastroenterology 2005; 129(3):969-984.

38. Brand S, Dambacher J, Beigel F et al. IL-22-mediated liver cell regeneration is abrogated by SOCS $-1 / 3$ overexpression in vitro. Am J Physiol Gastrointest Liver Physiol 2007; 292(4):G1019-G1028.
39. Sugimoto K, Ogawa A, Mizoguchi E et al. IL-22 ameliorates intestinal inflammation in a mouse model of ulcerative colitis. J Clin Invest 2008; 118(2):534-544.

40. Zheng Y, Valdez PA, Danilenko DM et al. Interleukin-22 mediates early host defense against attaching and effacing bacterial pathogens. Nat Med 2008; 14(3):282-289.

41. Cella M, Fuchs A, Vermi W et al. A human natural killer cell subset provides an innate source of IL-22 for mucosal immunity. Nature 2009; 457(7230):722-725.

42. Takatori H, Kanno Y, Watford WT et al. Lymphoid tissue inducerГÇôlike cells are an innate source of IL-17 and IL-22. J Exp Med 2009; 206(1):35-41.

43. Sonnenberg GF, Monticelli LA, Elloso MM, Fouser LA, Artis D. CD4(+) lymphoid tissue-inducer cells promote innate immunity in the gut. Immunity 2011; 34(1):122-134.

44. Cupedo T, Crellin NK, Papazian N et al. Human fetal lymphoid tissue-inducer cells are interleukin 17-producing precursors to RORC+ CD127+ natural killer-like cells. Nat Immunol 2009; 10(1):66-74.

45. Munoz M, Heimesaat MM, Danker K et al. Interleukin (IL)-23 mediates Toxoplasma gondii-induced immunopathology in the gut via matrixmetalloproteinase-2 and IL-22 but independent of IL-17. J Exp Med 2009; 206(13):3047-3059.

46. Whittington HA, Armstrong L, Uppington KM, Millar AB. Interleukin-22. American Journal of Respiratory Cell and Molecular Biology 2004; 31(2):220-226.

47. Aujla SJ, Chan YR, Zheng M et al. IL-22 mediates mucosal host defense against Gram-negative bacterial pneumonia. Nat Med 2008; 14(3):275-281.

48. Hoegl S, Bachmann M, Scheiermann P et al. Protective Properties of Inhaled IL-22 in a Model of Ventilator-Induced Lung Injury. American Journal of Respiratory Cell and Molecular Biology 2011; 44(3):369-376.

49. Sonnenberg GF, Nair MG, Kirn TJ, Zaph C, Fouser LA, Artis D. Pathological versus protective functions of IL-22 in airway inflammation are regulated by IL-17A. J Exp Med 2010; 207(6):1293-1305.

50. Besnard AG, Sabat R, Dumoutier L et al. Dual Role of IL-22 in allergic airway inflammation and its cross-talk with IL-17A. Am J Respir Crit Care Med 2011; 183(9):1153-1163.

51. Liang SC, Nickerson-Nutter C, Pittman DD et al. IL-22 Induces an Acute-Phase Response. J Immunol 2010; 185(9):5531-5538.

52. Kudva A, Scheller EV, Robinson KM et al. Influenza A inhibits Th17-mediated host defense against bacterial pneumonia in mice. J Immunol 2011; 186(3):1666-1674.

53. Zenewicz LA, Yancopoulos GD, Valenzuela DM, Murphy AJ, Karow M, Flavell RA. Interleukin-22 but not interleukin-17 provides protection to hepatocytes during acute liver inflammation. Immunity 2007; 27(4):647-659.

54. Ren $\mathrm{X}, \mathrm{Hu} \mathrm{B}$, Colletti LM. IL-22 is involved in liver regeneration after hepatectomy. American Journal of Physiology - Gastrointestinal and Liver Physiology 2010; 298(1):G74-G80.

55. Yang L, Zhang Y, Wang L et al. Amelioration of high fat diet induced liver lipogenesis and hepatic steatosis by interleukin-22. Journal of Hepatology 2010; 53(2):339-347.

56. $\mathrm{Ki} \mathrm{SH}$, Park $\mathrm{O}$, Zheng $\mathrm{M}$ et al. Interleukin-22 treatment ameliorates alcoholic liver injury in a murine model of chronic-binge ethanol feeding: Role of signal transducer and activator of transcription 3. Hepatology 2010; 52(4):1291-1300.

57. Park $\mathrm{O}$, Wang $\mathrm{H}$, Weng $\mathrm{H}$ et al. In vivo consequences of liver-specific interleukin-22 expression in mice: Implications for human liver disease progression. Hepatology 2011; 54(1):252-261.

58. Xu M, Morishima N, Mizoguchi I et al. Regulation of the development of acute hepatitis by IL-23 through IL-22 and IL-17 production. Eur J Immunol 2011.

59. Kong $X$, Feng D, Wang $\mathrm{H}$ et al. Interleukin-22 induces hepatic stellate cell senescence and restricts liver fibrosis. Hepatology 2012.

60. Feng D, Kong X, Weng H et al. Interleukin-22 Promotes Proliferation of Liver Stem/Progenitor Cells in Mice and Patients with Chronic Hepatitis B Virus Infection. Gastroenterology 2012.

61. Wolk K, Kunz S, Witte E, Friedrich M, Asadullah K, Sabat R. IL-22 Increases the Innate Immunity of Tissues. Immunity 2004; 21(2):241-254.

62. Liang SC, Tan XY, Luxenberg DP et al. Interleukin (IL)-22 and IL-17 are coexpressed by Th17 cells and cooperatively enhance expression of antimicrobial peptides. J Exp Med 2006; 203(10):2271-2279.

63. Madsen $\mathrm{P}$, Rasmussen $\mathrm{HH}$, Leffers $\mathrm{H}$ et al. Molecular cloning, occurrence, and expression of a novel partially secreted protein "psoriasin" that is highly up-regulated in psoriatic skin. J Invest Dermatol 1991; 97(4):701-712. 
64. Boniface K, Guignouard E, Pedretti N et al. A role for T cell-derived interleukin 22 in psoriatic skin inflammation. Clin Exp Immunol 2007; 150(3):407-415.

65. Ma HL, Liang S, Li J et al. IL-22 is required for Th17 cell-mediated pathology in a mouse model of psoriasis-like skin inflammation. J Clin Invest 2008; 118(2):597-607.

66. Niebuhr M, Scharonow H, Gathmann M, Mamerow D, Werfel T. Staphylococcal exotoxins are strong inducers of IL-22: A-ápotential role in atopic dermatitis. Journal of Allergy and Clinical Immunology 2010; 126(6):1176-1183.

67. Nograles KE, Zaba LC, Shemer A et al. IL-22 producing T22 T cells account for upregulated IL-22 in atopic dermatitis despite reduced IL-17 producing TH17 T cells. J Allergy Clin Immunol 2009; 123(6):1244-1252. 